\title{
Cognitive Function Outcomes of Post-operative Mild to Moderate Traumatic Brain Injury using Combination of Mini-mental State Examination, Digit Span, and Constructional Praxis
}

\author{
Achmad Adam ${ }^{1}$, Christian Ariono ${ }^{2}$, Muhammad Z. Arifin ${ }^{1}$, Ahmad Faried ${ }^{1 *}$ \\ ${ }^{1}$ Department of Neurosurgery, Faculty of Medicine, Universitas Padjadjaran, Dr. Hasan Sadikin Hospital, Bandung, West Java, \\ Indonesia; ${ }^{2}$ Department of Neurosurgery, Mandaya Royal Hospital Puri, Tangerang, Banten, Indonesia
}

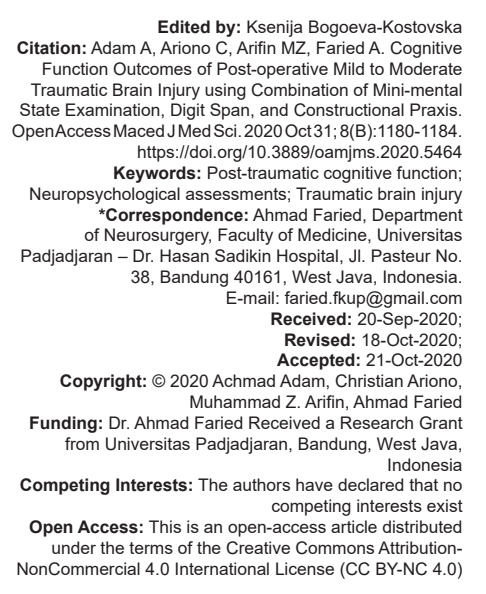

\section{Introduction}

Head injuries have varying meanings or terminology. According to Field $\mathrm{JH}$ in 1976, brain injury is a trauma that causes the risk of damage to the brain [1]. Ommaya et al., 2002, defines a brain injury as the result of external mechanical forces affecting the cranium and intracranial contents that can cause temporary or permanent disruption, functional disability, or inability to adapt psychosocially [2]. Further explanation, traumatic brain injury (TBI) is an external mechanical force and not a degenerative or congenital disorder affecting the brain that may cause permanent or temporary damage to cognitive, physical, and psychosocial functions; related to diminishing or changing levels of consciousness [3], [4].

Faried et al., in his 2017 study, at Dr. Hasan Sadikin Hospital (RSHS), Bandung, from January 2012 to December 2017, there were 9006 cases of TBI with 6783 males $(75.32 \%)$ and 2223 females $(24.68 \%)$. The number of patients in each category (mild, moderate, and severe) was 5846 (64.91\%), 2111 (23.44\%), and $1049(11.65 \%)$, respectively, with 2444 cases $(27.15 \%)$ had intracranial hemorrhage lesions and 1105 cases $(12.27 \%)$ were managed surgically, with overall mortality rate $1.88 \%$ (170) [5]. Taking into consideration of variability in TBI cases, a comprehensive neuropsychological assessment is needed to allow a systematic analysis of patients cognitive functions. At present, the TBI management has shifted not only to save lives but also to improve the quality of life after the injuries [6].

The cognitive function can be interpreted as a sublime human function consisting of various complex mental processes for thinking, speech, behavior, and planning. Cognitive function has five main domains that can be measured, namely, attention, memory, language, Visuospatial, and executive functions. The cognitive function provides an overview of the level of intellectual functions. Impaired cognitive function is a decrease in intellectual ability that can be examined using the neuropsychological test. The cognition domain in patients with $\mathrm{TBI}$ is expected to be disturbed if the 
results are lower than the normal value. The utilization of mini-mental state examination (MMSE), digit span (DS), and constructional praxis (CP) test objectively provides a whole picture regarding the scale of cognitive impairment in patients with TBI [7]. Systematic evaluation of neuropsychological assessments, namely, MMSE, $\mathrm{DS}$, and CP, will help to monitor neuropsychological profiles in patients with TBI.

\section{Methods}

This was a single-institution prospective study and had beenapproved byourinstitutionethicalcommittee (ethical approval No. LB.02.01/X.6.5/103/2019). We included mild- and moderate-TBI patients with surgical intervention, not under medication, aged 15-75 yearsold, fully alert Glasgow Coma Scale (GCS) 15 at the test was done with written informed consent. Patients with multiple injury, epilepsy, dementia, and mental illness prior TBI or incompletion of cognitive assessment were excluded from the study. Patient data were collected from January to August 2019; 80 mildto moderate-TBI patients who had undergone surgery, 79 patients included, and we excluded one patient due to incompletion of cognitive assessment. All subjects filled a questionnaire of sociodemographic and medical record. The cognitive function was assessed using the following tests:

\section{MMSE}

MMSE evaluates the global status of cognitive function, including attention, temporal and spatial orientation, naming, memory, writing, and copy, following verbal and written commands [8].

\section{DS}

DS is subtest of Wechsler Adult Intelligence Scale-Third Edition (WAIS-III) [9]. DS evaluates the attention and working memory, testing of a number repetition constituted DS forward and DS backward.

\section{3-D CP}

Is a broad concept which has been applied to a number of different types of activities [10]. These activities share common characteristics, they require the patient to assemble, join, or articulate parts to form a single unitary structure.

We analyzed the correlations between clinical variables and neuropsychological tests among patients. We used Microsoft Excel 2010 and SPSS ver. 23.0 (Armonk, NY: IBM Corp., 2013) for statistical analysis. The statistical significance was considered at $p<0.05$.

\section{Results}

\section{The clinical characteristics}

The clinical characteristics, including age, gender, educational level, time to surgery, length of stay (LOS), severity, lesion type, and location was presented in Table 1. There were 61 male patients $(77.2 \%)$ and 18 female patients (22.8\%), predominantly in young adults (mean $=28.4$ years old, range between 15 and 74 years old).

Table 1: The characteristics of the subjects

\begin{tabular}{|c|c|c|}
\hline Characteristics & $\mathrm{n}=79$ & Percentage \\
\hline \multicolumn{3}{|l|}{ Gender } \\
\hline Male & 61 & 77.2 \\
\hline Female & 18 & 22.8 \\
\hline \multicolumn{3}{|l|}{ Age } \\
\hline$<20$ years old & 26 & 32.9 \\
\hline $20-30$ years old & 24 & 30.4 \\
\hline $31-40$ years old & 18 & 22.8 \\
\hline $41-50$ years old & 4 & 5.1 \\
\hline $51-60$ years old & 4 & 5.1 \\
\hline$>60$ years old & 3 & 3.8 \\
\hline \multicolumn{3}{|l|}{ Education } \\
\hline Elementary school & 3 & 3.8 \\
\hline Junior high school & 23 & 29.1 \\
\hline Senior high school & 44 & 55.7 \\
\hline Collage & 9 & 11.4 \\
\hline \multicolumn{3}{|l|}{ Time to surgery } \\
\hline $2-24 \mathrm{~h}$ & 56 & 70.9 \\
\hline $24-48 \mathrm{~h}$ & 9 & 11.4 \\
\hline$>48 \mathrm{~h}$ & 14 & 17.7 \\
\hline \multicolumn{3}{|l|}{ LOS } \\
\hline$<7$ days & 22 & 27.8 \\
\hline $7-14$ days & 52 & 65.8 \\
\hline$>14$ days & 5 & 6.3 \\
\hline \multicolumn{3}{|l|}{ Severity of TBI } \\
\hline Mild & 24 & 30.4 \\
\hline Moderate & 55 & 69.6 \\
\hline \multicolumn{3}{|l|}{ Lesion } \\
\hline $\mathrm{EDH}$ & 37 & 46.8 \\
\hline Compressed fracture & 17 & 21.5 \\
\hline Intracerebral & 6 & 7.6 \\
\hline $\mathrm{SDH}$ & 13 & 16.5 \\
\hline Mix & 6 & 7.6 \\
\hline \multicolumn{3}{|l|}{ Location of the lesion } \\
\hline Frontal & 26 & 32.9 \\
\hline Occipital & 3 & 3.8 \\
\hline Parietal & 30 & 38.0 \\
\hline Temporal & 11 & 13.9 \\
\hline Mix & 9 & 11.4 \\
\hline
\end{tabular}

In this study, we obtained that age has a significant correlation with cognitive function on MMSE $(p=0.049)$ and DS test $(p=0.015)$; Pearson correlation coefficients were used; on the other hand, age is not correlated with CP test $(p=0.093)$. Our results suggest that the older the patient', the probability of having cognitive impairment increases.

To observe a potential protective role of educational background in TBI-associated cognitive deficits, patients were divided into four groups - elementary (6 years), junior high school (9 years), senior high school (12 years), and colleague ( $\geq 12$ years). Three $(3.8 \%)$ patients had accomplished basic education (6 years of formal education), $23(29.1 \%)$ patients had 9 years of 
formal education, $44(55.7 \%)$ patients had 12 years of education, and $9(11.4 \%)$ patients had $\geq 12$ years of education. Significant differences were found in MMSE $(p=0.008)$ and DS $(p=0.000)$, but not in CP ( $p=0.121)$; our results showed that the lower educational background was more likely to have cognitive impairment.

There was no statistically significant correlation between cognitive function and time to surgery, and also LOS. The majority of patients (56 of 79 ) were operated $<24 \mathrm{~h}$ after the insult. Most of the patients (52 of 79) were hospitalized between 7 and 14 days, with the shortest was 4 days and the longest was 22 days. Of the 79 subjects, there were $24(30.5 \%)$ mild TBI cases and the remaining $55(69.6 \%)$ moderate $\mathrm{TBI}$ cases. The most common type of lesion was epidural hemorrhage (EDH), which was found in 37 cases $(46.8 \%)$ of the patients. In this study, the majority of the lesions were in the parietal $(38 \%)$ followed by the frontal $(32.9 \%)$ regions.

\section{Correlation between cognitive functions with severity of $T B I$}

The four main domains of cognitive function consist of input, storage, processing (selecting, combining, linking data in several ways), and output so that (1) receptive function refers to the ability to choose, obtain, classify, and integrate information; (2) memory and learning refers to information storage and recall; (3) thinking includes mental organization and reorganization of the information; and (4) expressive function is the way in which information is communicated or done. Although each function includes a different class of behavior, they always work together and depend on each other [11].

In this study, we assessed the cognitive performance using: MMSE, DS, and CP. Based on MMSE, most subjects were within the normal limit, but there were $5(6.3 \%)$ and $2(2.5 \%)$ patients experiencing cognitive impairment in mild- and moderate-TBI, respectively. Based on the DS test of 79 patients, $11(13.9 \%)$ subjects had attention problems. Based on CP test, the majority of patients were normal, but there were $19(24.1 \%)$ and $4(5.1 \%)$ patients who experienced mild- and moderate-disruption, respectively (Table 2 ).

Table 2: Correlation between cognitive functions with severity of traumatic brain injury

\begin{tabular}{|c|c|c|c|c|}
\hline \multirow[t]{2}{*}{ Cognitive functions } & & \multicolumn{2}{|c|}{ Traumatic brain injury (\%) } & \multirow[t]{2}{*}{ p-value } \\
\hline & & Mild $(n=24)$ & Moderate $(n=55)$ & \\
\hline \multicolumn{5}{|l|}{ MMSE (\%) } \\
\hline Normal & $(\mathrm{n}=72 ; 91.1)$ & $24(100.0)$ & $48(87.3)$ & 0.187 \\
\hline Mild & $(n=5 ; 6.3)$ & $0(0.0)$ & $5(9.1)$ & \\
\hline Moderate & $(n=2 ; 2.5)$ & $0(0.0)$ & $2(3.6)$ & \\
\hline \multicolumn{5}{|l|}{ Digit span (\%) } \\
\hline Normal & $(n=68 ; 86.1)$ & $24(100.0)$ & $44(80.0)$ & $0.018^{*}$ \\
\hline Attention disorder & $(\mathrm{n}=11 ; 13.9)$ & $0(0.0)$ & $11(20.0)$ & \\
\hline \multicolumn{5}{|c|}{ Constructional praxis (\%) } \\
\hline Normal & $(n=56 ; 70.9)$ & $22(91.7)$ & $34(61.8)$ & $0.025^{*}$ \\
\hline Mild & $(\mathrm{n}=19 ; 24.1)$ & $2(8.3 \%)$ & $17(30.9)$ & \\
\hline Moderate & $(\mathrm{n}=4 ; 5.1)$ & $0(0.0 \%)$ & $4(7.3)$ & \\
\hline
\end{tabular}

The correlation between MMSE score with TBI was not significant ( $p=0.187$ ). On the other hand, the correlation between DS with TBI was significant $(p=0.018)$. From the analysis of CP, the degree of head injury had a significant correlation $(p=0.025)$ with the occurrence of mild- and moderate-disturbances.

\section{Correlation of each cognitive function (DS, MMSE, and CP) with TBI lesions and locations}

The correlation between DS score with type of TBI lesions $(p=0.460)$ or locations $(p=0.649)$ were not significant. The correlation between MMSE score with type of TBI lesions $(p=0.225)$ or locations $(p=0.926)$ were not significant; Pearson correlation coefficients were used.

We observed a significant correlation between the type of lesions and cognitive function disorder based on CP test ( $p=0.009)$; EDH has a predominantly cognitive impairment based on CP test, whereas, in depressed fracture, there was no cognitive impairment. The locations of the lesion itself, somehow, were not related to cognitive function disorder based on $\mathrm{CP}$ test ( $p=0.159)$. The intracranial lesion locations that had the highest percentage of cognitive impairment, based on CP test, are in the parietal region, whereas in lesions located in the occipital, post-traumatic cognitive impairment was not found (Table 3).

Table 3: Correlation of DS, MMSE, and CP with TBI lesions and locations

\begin{tabular}{|c|c|c|c|c|}
\hline & \multicolumn{3}{|l|}{ DS (\%) } & \multirow[t]{2}{*}{$p$-value } \\
\hline & \multicolumn{3}{|c|}{ Normal $(n=68)$ Attention disorder $(n=11)$} & \\
\hline \multicolumn{5}{|l|}{ Lesion } \\
\hline Epidural hemorrhage & $30(44.1)$ & \multicolumn{2}{|l|}{$7(63.6)$} & \multirow[t]{5}{*}{0.460} \\
\hline Depress fracture & $17(25.0)$ & $0(0.0)$ & & \\
\hline Intracerebral hemorrhage & $5(7.4)$ & $1(9.1)$ & & \\
\hline Subdural hemorrhage & $11(16.2)$ & $2(18.2)$ & & \\
\hline Mix & $5(7.4)$ & $1(9.1)$ & & \\
\hline \multicolumn{5}{|l|}{ Location } \\
\hline Frontal & $24(35.3)$ & $2(18.2)$ & & \multirow[t]{5}{*}{0.649} \\
\hline Occipital & $3(4.4)$ & $0(0.0)$ & & \\
\hline Parietal & $24(35.3)$ & $6(54.5)$ & & \\
\hline Temporal & $9(13.2)$ & $2(18.2)$ & & \\
\hline \multirow{3}{*}{ Mix } & $8(11.8)$ & $1(9.1)$ & & \\
\hline & \multicolumn{3}{|l|}{ MMSE (\%) } & \\
\hline & Normal $(n=72)$ & Mild $(n=5)$ & Moderate $(n=2)$ & \\
\hline \multicolumn{5}{|c|}{ 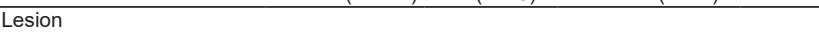 } \\
\hline Epidural hemorrhage & $34(47.2)$ & $3(60.0)$ & $0(0.0)$ & \multirow[t]{5}{*}{0.225} \\
\hline Depress fracture & $17(23.6)$ & $0(0.0)$ & $0(0.0)$ & \\
\hline Intracerebral hemorrhage & $5(6.9)$ & $0(0.0)$ & $1(20.0)$ & \\
\hline Subdural hemorrhage & $11(15.3)$ & $1(20.0)$ & $1(20.0)$ & \\
\hline Mix & $5(6.9)$ & $1(20.0)$ & $0(0.0)$ & \\
\hline \multicolumn{5}{|l|}{ Location } \\
\hline Frontal & $24(33.3)$ & $1(20.0)$ & $1(50.0)$ & \multirow[t]{5}{*}{0.926} \\
\hline Occipital & $3(4.2)$ & $0(0.0)$ & $0(0.0)$ & \\
\hline Parietal & $26(36.1)$ & $3(60.0)$ & $1(50.0)$ & \\
\hline Temporal & $11(15.3)$ & $0(0.0)$ & $0(0.0)$ & \\
\hline \multirow[t]{3}{*}{ Mix } & $8(11.1)$ & $1(20.0)$ & $0(0.0)$ & \\
\hline & \multicolumn{3}{|l|}{$\mathrm{CP}(\%)$} & \\
\hline & Normal $(n=56)$ & Mild $(n=19)$ & Moderate $(n=4)$ & \\
\hline \multicolumn{5}{|l|}{ Lesion } \\
\hline Epidural hemorrhage & $25(44.6)$ & $11(57.9)$ & $1(25.0)$ & \multirow[t]{5}{*}{$0.009^{*}$} \\
\hline Depress fracture & $17(30.4)$ & $0(0.0)$ & $0(0.0)$ & \\
\hline Intracerebral hemorrhage & $5(8.9)$ & $0(0.0)$ & $1(25.0)$ & \\
\hline Subdural hemorrhage & $8(14.3)$ & $4(21.1)$ & $1(25.0)$ & \\
\hline Mix & $1(1.8)$ & $4(21.1)$ & $1(25.0)$ & \\
\hline \multicolumn{5}{|l|}{ Location } \\
\hline Frontal & $22(39.3)$ & $2(10.5)$ & $2(50.0)$ & \multirow[t]{5}{*}{0.159} \\
\hline Occipital & $3(5.4)$ & $0(0.0)$ & $0(0.0)$ & \\
\hline Parietal & $18(32.1)$ & $11(57.9)$ & $1(25.0)$ & \\
\hline Temporal & $9(16.1)$ & $2(10.5)$ & $0(0.0)$ & \\
\hline Mix & $4(7.1)$ & $4(21.1)$ & $1(25.0)$ & \\
\hline
\end{tabular}




\section{Discussion}

In our study, the proportion of our patient was composed mainly by male as many as $61(77.2 \%)$ and 18 women $(22.8 \%)$ patients; with a mean age of 28.4 years, ranging from 15 to 74 years with the highest age group of $15-20$ years (32.9\%). The distribution of patient's age in our study is consistent with what was stated by Taylor et al., in 2017, that head trauma is more common in male and in young adults [12]. Most of the patient $(55.7 \%)$ had 12 or more years of education and $(69.6 \%)$ had moderate TBI.

Cognitive disorders due to TBI are a source of morbidity in individual, family members, and also the community. Disturbances in attention, memory, and executive function are the most common neurocognitive disorders of all degrees of TBI. Disturbances in attention and memory are complicated problems because the interference from this basic cognitive function can disturb executive function and communication [13]. As far as we know, our study is the first attempt to observe the incidence of cognitive impairment (using a combination of MMSE, DS, and CP test) following in patients with surgically-treated TBI in Indonesian population.

In this study, we found a significant correlation between the severity of TBI and cognitive performance, particularly based on DS and CP tests; patients with moderate $\mathrm{TBI}$ are more likely to have a higher risk of cognitive impairment. Goldstein FC, in 2001, reported that in a patient with age more than 50 years old, the low GCS values and the presence of intracranial pathological lesions are strongly associated with cognitive outcomes, while the duration of post-traumatic amnesia and decreased consciousness has no meaningful consequence for cognitive outcomes [14].

We found that age had a significant correlation with post-traumatic cognitive function, particularly on DS and MMSE tests. Overall, younger ages are more protected to post-traumatic cognitive impairment. In 2013, Kinsella reported at 3 months following mild TBI, older adults are at risk of poor cognitive performance, but this is substantially accounted for by pre-existing cognitive status to injury or the general negative effects of multi-system trauma [15].

We also found that an educational background may influence in cognitive function in a patient with TBI. In agreement with our findings, Sumowski et al. observed that a higher level of education attenuated the TBI deleterious effects [16]. Moderate to severe TBI patients and higher education performed better in cognitive functions; as observed by Leary et al., years of education were associated with measures of memory, learning, working memory, and processing speed in TBI patients [17]. Education is one of the factors that constitute the so-called "cognitive reserve," a protective factor associated with better TBI outcome [17]. Other studies also indicated that educational background influences the cognitive outcome. Cardoso et al., in 2018, conducted a study of 53 mild TBI patients (ages 19-64 years) and compared with 28 control populations to assess posttraumatic cognitive function-assessed with an MMSE, DS, Frontal Assessment Battery, and Visual Memory Test - in the acute phase (under $24 \mathrm{~h}$ ); the results in mild TBI patients have worse cognitive performance compared with controls and patients with lower levels of education have higher levels of cognitive impairment [18].

In this study, we found that intracranial lesion, especially EDH, is associated with worse post-traumatic cognitive function assessed using CP test. An EDH often disturbs brain function because of compression, although there is generally little intrinsic brain damage. If compression is relieved in time, full recovery will more likely occur. Miotto et al., in 2010, conducted a cognitive impairment study in patients with mild- and moderateTBI; patients with the frontotemporoparietal intracranial lesions have the heaviest cognitive impairment related to memory and executive function [19].

\section{Conclusions}

In this study (using combination of MMP, DS, and CP test), we showed that moderate TBI patients present with more deficits of cognitive function versus mild TBI patients, episodic memory, and executive function in particular. Time to surgery and LOS have less influence during the period. In contrast, the age and educational background influence the cognition; the younger of age and the higher level of education have the protection roles; emphasize the importance of complementing the clinical exams and neuroimaging using investigational tools for holistic neuropsychological assessments and effort to preserved functions for adequate managing such as rehabilitation programs.

\section{Ethical statement}

This study was approved by the Faculty of Medicine, Universitas Padjadjaran ethics committee and has been performed in according to ethical standards laid down Helsinki Declaration 1964.

\section{Authors' contributions}

All authors had examined, treated, observed, and follow-up the patients. All authors participated in 
writing the manuscript, had read, and approved the final manuscript.

\section{References}

1. Field JH. Epidemiology of head injury in England and Wales. London: Department of Health and Social Security, Her Majesty's Stationery Office; 1976.

2. Ommaya AK, Goldsmith W, Thibault L. Biomechanics and neuropathology of adult and paediatric head injury. $\mathrm{Br} J$ Neurosurg. 2002;16(3):220-42. https://doi. org/10.1080/02688690220148824

PMid:12201393

3. Fearnside RR, Simpson DA. Epidemiology. In: Reilly P, Bullock R, editors. Head Injury: Patophysiology and Management. London: Hodder Arnold; 2007. p. 4-9.

4. Bullock MR, Hovda DA. Introduction to traumatic brain injury. In: Winn H, Beger MS, Dacey RG, editors. Youman's Neurological Surgery. Philadelphia, PA: Elsevier Saunders; 2011. p. 3267-9. https://doi.org/10.1016/b978-1-4160-5316-3.00325-7

5. Faried A, Halim D, Widjaya IA, Badri RF, Sulaiman SF, Arifin MZ. Correlation between the skull base fracture and the incidence of intracranial hemorrhage in patients with traumatic brain injury. Chin J Traumatol. 2019;22(5):286-9. https://doi.org/10.1016/j. cjtee.2019.05.006

PMid:31521457

6. McInnes K, Friesen CL, MacKenzie DE, Westwood DA, Boe SG. Mild traumatic brain injury (mTBI) and chronic cognitive impairment: A scoping review. PLoS One. 2017;12(4):e0174847. https://doi.org/10.1371/journal.pone.0174847 PMid:28399158

7. Andrewes D. Neurophysiology, From Theory to Practice. United States: Physiology Press Taylor and Francis Group; 2001.

8. Folstein MF,FolsteinSE,McHughPR.Mini-mentalstate.Apractical method for grading the cognitive state of patients for the clinician J Psychiatr Res. 1975;12(3):189-98. https://doi.org/10.1002/ (sici)1099-1166(199805)13:5<285::aid-gps753>3.0.co;2-v PMid:1202204

9. Figueiredo VL, Nascimento E. Performances in the forward and backward digit span in the WISC-III and WAIS-III. Psicologia (Portuguese). 2007;23(3):313-8.

10. Carlesimo GA, Caltagirone C, Gainotti G. The Mental Deterioration Battery: Normative data, diagnostic reliability and qualitative analyses of cognitive impairment. The group for the standardization of the mental deterioration battery. Eur Neurol. 1996;36(6):378-84. https://doi.org/10.1159/000117297 PMid:8954307

11. Lezak MD, Howieson DB, Loring DW. Neuropsychological Assessment. New York: Oxford University Press; 2004. p. 15-37.

12. Taylor CA, Bell JM, Breiding MJ, Xu L. Traumatic brain injuryrelated emergency department visits, hospitalizations, and deaths United States, 2007 and 2013. MMWR Surveill Summ. 2017;66(9):1-16. https://doi.org/10.15585/mmwr.ss6609a1 PMid:28301451

13. Arciniegas DB, Held K, Wagner $P$. Cognitive impairment following traumatic brain injury. Curr Treat Options Neurol. 2002;4(1):43-57. https://doi.org/10.1007/s11940-002-0004-6 PMid:11734103

14. Goldstein FC, Levin HS. Cognitive outcome after mild and moderate traumatic brain injury in older adults. J Clin Exp Neuropsychol. 2001;23(6):739-53. https://doi.org/10.1076/ jcen.23.6.739.1028

PMid:11910541

15. Kinsella GJ, Olver J, Ong B, Gruen R, Hammersley E. Mild traumatic brain injury in older adults: Early cognitive outcome. J Int Neuropsychol Soc. 2014;20(6):663-71. https://doi. org/10.1017/s1355617714000447

PMid:24834461

16. Sumowski JF, Chiaravalloti N, Krch D, Paxton J, Deluca J. Education attenuates the negative impact of traumatic brain injury on cognitive status. Arch Phys Med Rehabil. 2013;94(12):25624. https://doi.org/10.1016/j.apmr.2013.07.023 PMid:23932968

17. Leary JB, Kim GY, Bradley CL, Hussain UZ, Sacco M, Bernad M, et al. The association of cognitive reserve in chronic-phase functional and neuropsychological outcomes following traumatic brain injury. J Head Trauma Rehabil. 2018;33(1):E28-35. https:// doi.org/10.1097/htr.0000000000000329 PMid:28731870

18. Cardoso MG, Faleiro RM, de Paula JJ, Kummer A, Caramelli $P$, Teixeira AL, et al. Cognitive impairment following acute mild traumatic brain injury. Front Neurol. 2019;10:198. https://doi. org/10.3389/fneur.2019.00198 PMid:30906278

19. Miotto EC, Cinalli FZ, Serrao VT, Benute GG, Lucia MC, Scaff M Cognitive deficits in patients with mild to moderate traumatic brain injury. Arq Neuropsiquiatr. 2010;68(6):862-8. https://doi. org/10.1590/s0004-282×2010000600006

PMid:21243242 